CMS

12,1

\section{4}

\title{
Promotion of secure software development assimilation: stimulating individual motivation
}

\author{
Mingqiu Song, Penghua Wang and Peng Yang \\ Faculty of Management and Economics, \\ Dalian University of Technology, Dalian, China
}

\begin{abstract}
Purpose - The purpose of this study was to establish a Technology-Organization-Personality model of secure software development (SSD) innovation assimilation at the level of individual motivation. The model identifies individual psychological motivation, which influences innovation assimilation intention and behavior. It constitutes an organizational management view of SSD innovation assimilation from individual psychological motivation perspective.

Design/methodology/approach - An empirical study was employed to verify the assumption model. Semi-structured user interviews were conducted with some security experts to consult their advice and obtain the measurement scales. And questionnaires were circulated at a focus group meeting and among some software security professionals by email. Of 230 questionnaires that were answered, 215 could be used. IBM SPSS 19.0 and AMOS 17.0 were used alternately to analyze the data. Structural equation model was employed to verify the hypotheses of the model.

Findings - Results reveal that two types of individual motivation can influence SSD innovation assimilation, namely, potential organization support and individual needs. Furthermore, absorption capability was found to play a regulated function in the transition of SSD assimilation intention to behavior.

Originality/value - The findings reveal how individual motivation plays an important role in promoting complex innovation assimilation. It fills the gap of the research on organizational assimilation behavior and individual motivation in the context of SSD complex innovation, and provides management of software development organization with empirically based conceptualization to guide their personnel incentive policymaking.
\end{abstract}

Keywords Perceived organizational support, Individual motivation, Absorption capability, Innovation assimilation, Secure software development

Paper type Research paper

\section{Introduction}

Motivation is regarded as the internal motive force that influences the originator, direction and continuity of behavior (Deci et al., 1980). In the field of organizational behavior, motivation, as a verb, is called "encouragement" or "incentive", that is, by stimulating and

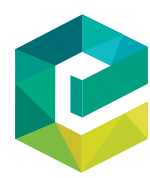
encouraging people to generate an internal driving force (Scott, 2005). Motivation is the intrinsic determinant of behavior (Davis et al., 2006). It can explain why people behave in

(C) Mingqiu Song, Penghua Wang and Peng Yang. Published by Emerald Publishing Limited. This article is published under the Creative Commons Attribution (CC BY 4.0) licence. Anyone may reproduce, distribute, translate and create derivative works of this article (for both commercial and non-commercial purposes), subject to full attribution to the original publication and authors. The full terms of this licence may be seen at http://creativecommons.org/licences/by/4.0/legalcode

This research was supported by the National Science Foundation of China (Grant no. 71171028). 
certain ways and can also predict future behavior. Any management policy that is irrelevant to behavior is not valid (Karl, 1979). Considerable study has been conducted on motivation; furthermore, its direct and indirect effects on behavior mainly focus on intrinsic and extrinsic motivations. Intrinsic motivation such as individual awareness, attitude and cognitive ability directly affect behavior and, subsequently, innovation deployment (Ke and Wei, 2015; Maruping and Magni, 2015). While extrinsic motivation is associated with external pressures, which are usually the result of organization management policy (Amabile, 1985), organization management policy directly affects organization behavior (Li et al., 2013; Hsieh and Wang, 2007).

Assimilation is the extent to which a firm has progressed through the stages of innovation deployment - from initial awareness and adoption to general deployment and routinization (Fichman and Carroll, 1999). Assimilation is very different from adoption, which refers to management's authorization of the purchase of technology rather than whether the firm has actually deployed the technology or moved beyond an early stage toward routinizing the technology for everyday use (Rogers, 1995). Assimilation is an organizational process that progresses from individual organizational members hearing about innovation to the full acceptance, utilization and institutionalization of the innovation in the organization (Meyer and Goes, 1988). Complex technology innovation, in particular, involves an immense assimilation disparity between the adoption of the technology and its complete implementation (Fichman and Kemerer, 1999). The process of assimilation for complex technology is dependent on primary individual adoption to the company innovation adoption as a whole (GalUvan, 2001).

Secure software development (SSD) innovation is a typical complex technology innovation in information system development methodology; it includes a series of software development methodology such as Microsoft's Security Development Lifecycle (SDL), Macgraw's Build Security In (BSI), Comprehesive Lightweight Application Security Process (CLASP) of Open Web Application Security Project (OWASP), Build Security In Maturity Model (BSIMM) and Software Assurance Maturity Model (SAMM). SSD embeds security factors in the whole software development life cycle. It can provide an effective way to reduce software security vulnerabilities and ensure high intrinsic security of software production (Tornatzky et al., 1990). SSD is at the stage of awareness and deployment. It is so hard for SSD dissemination and application in that it takes about 10-20 years to spread among the software development organizations from its initial appearance to wide range of applications. With the exception of immature methodology and technology, some nontechnical activities such as organizational and individual behavior also play an important role in SSD assimilation (Duan et al., 2001; Liu et al., 2011). Although some studies have been conducted on SSD adoption from organizational management and environmental framework (Ricahrd and Ryan, 2000), there is scarcity of research on potential motivation from the perspective of psychology in SSD assimilation. The latter is very important for understanding how to stimulate individual motivation to change the intention of assimilation of complex innovation into assimilation behavior.

To resolve this issue, we studied a Technology-Organization-Environment (TOE) framework, dig down to find out potential psychological determinants and establish a Technology-Organization-Personality (TOP) model of SSD innovation assimilation from individual motivation perspective. We have contributed to the existing literature in the following three aspects. First, we filled a gap of innovation assimilation theory in the literature by examining potential individual psychological motivation as a determining factor and extending the TOE framework from the level of organizational management to the individual psychological level. It can establish a link between individual psychological motivation and organizational behavior. Second, our research helps to 
CMS

12,1

explain how to stimulate individual motivation so as to deploy SSD innovation by taking these determinants such as arousing the employees' interests and adopting SSD innovation in an enjoyable way into consideration. And to be long for the support of enterprise leaders and peers, which strengthens the drive, is also explained. Finally, we interpreted the regulated role that individual absorption capability might play in SSD innovation assimilation. With further research on moderating effects, the model could explain SSD assimilation more scientifically and adequately. The research results can provide management of software development organization with empirically based conceptualization to guide their personnel incentive policymaking.

To obtain a representative sample with qualities that would yield data to address our research question, we selected some well-known software engineers, security engineers and consultants from software organizations as well as senior managers in related enterprises to take part in the survey. The investigation was conducted by interviewing some security professionals and circulating questionnaires in a group meeting at the 2015 China Software and Information Service Fair and by email. We are of the opinion that the results would be useful for the policymaking regarding activation principles in software development organizations. It would also be beneficial to scholars of information security and organizational behavior who are interested in SSD.

\section{Theoretical analysis and research hypotheses}

The TOE framework is usually employed to interpret organizational innovation assimilation behavior, which studies factors affecting organizational behavior from three dimensions, namely, technology, organization and environment (Duan et al., 2001; Liu et al., 2011; Ricahrd and Ryan, 2000). The TOE framework was created by Tornatzky et al. (1990). It describes factors that influence technology adoption and the likelihood thereof. It also describes the process by which a firm adopts and implements technological innovations that are influenced by the technological, organizational and environmental contexts (Tornatzky et al., 1990). These three elements influence the way a firm perceives the need for new technology and, accordingly, searches for and adopts it. Although some existing theories such as goal-setting theory could also be exploited to explain innovation adoption and motivation, it is strengthened to set effective goals, which represents specific, measurable, attainable, realistic and tangible goals with a target date (Locke and Latham, 2002; DuBrin, 2012). The most is to be S.M.A.R.T, according to the goal-setting expert Anthony (2012). Regarding SSD innovation is a complex and challenging task, in some cases, even local security experts do not know the best solution, let alone the developer who may be vulnerable for security issues. In this situation, the result mainly depends on individual creativity, and the goal-setting theory does not work well. So, we use TOE framework to be our ground theory to build our research model.

In the TOE framework, technical dimension focuses on internal and external technical characteristics related to enterprises such as usability, compatibility and complexity (Gagnon and Dragon, 2002). The organizational dimension includes description features of the enterprise such as scale, business scope and management structure (Song et al., 2014). The environment dimension is an enterprise's business operation environment and involves factors such as industry traits and market structure (Ives and Jarvenpaa, 1991).

To identify the influencing factors of SSD innovation assimilation on individual motivation level, we conducted a longitudinal study based on the three dimensions of the TOE.

\section{Absorption capacity}

According to the technical dimension, SSD is a complicated technological innovation. If an organization wants to enjoy the full benefit of SSD innovation, team members engage more 
in their work and exhibit more creativity in completing their specific tasks (Zhang et al., 2017). Individual skill level directly affects the degree of acceptance difficulty of SSD and thereafter affects the SSD assimilation of the whole organization (Bosua et al., 2013). To describe individual skill levels, absorption capacity, a concept about learning and innovation, is advanced to explain that individual absorption capacity is different from person to person during innovation assimilation (Wesley and Levinthal, 1990; Liu et al., 2011). Individuals with strong absorption capacity are able to obtain more individual skills, exhibit more creativity and show strong willing to adopt innovation. Absorption capacity can also be interpreted as self-efficacy, which reflects the possibility of the user feeling anxious and uncertain regarding the change. If they have high self-efficacy, they may feel more confident and find it easier to adopt and learn to use the innovation (Bandura, 1995; Eby et al., 1999).

Absorption capability plays an important role in the transformation of the users' potential assimilation intention to their actual assimilation behavior. Although Davis' technology acceptance model (Davis, 1989) proposes that system use is determined by behavioral intention, it does not mean users will exhibit assimilation behavior even if they do have assimilation intention (Lapointe and Rivard, 2007). This may be the result of their weak absorption capability and/or the complexity of the SSD technology. Therefore, we suggest that absorption capacity affects individual SSD innovation assimilation intention first and then affects individual SSD assimilation behavior:

H1. Individual SSD innovation assimilation intention has a positive effect on individual SSD innovation assimilation behavior.

H2. Absorption capacity has a positive regulated effect on the conversion from individual SSD innovation assimilation intention to assimilation behavior.

\section{Organizational characteristics}

According to the organizational dimension, employee involvement climate strengthens the relationship between promotion focus and thriving, which, in turn, is positively related to innovation (Wallace et al., 2016). Internal communication between the management and employee plays an important role in organizational innovation (Mishra et al., 2014). The organizational features related to individual involvement include decision-making participation, perceived organizational support and perceived organizational justice (Ajzen, 2002). The three factors outlined above are summarized in perceived behavioral control, which is an important factor that affects behavioral intention (Ajzen, 2002; Utman, 1997). Organizational support for change represents the external means of achieving control of the changed situation (Rhoades and Eisenberger, 2002). It has a certain influence on adoption intention. Decision-making participation, perceived organizational support and perceived organizational justice also have important effects on an employee's work motivation and performance. Higher perceived organizational support can promote an employee's positive emotions and enthusiasm (Rhoades and Eisenberger, 2002); these types of positive emotions help improve the quality of intrinsic work motivation (Eby et al., 1999; Maslow, 1943). Thus, based on the level of individual motivation, we propose three hypotheses concerning the perceived organizational activities that influence behavioral intention:

H3. Perceived organizational support has a positive effect on individual SSD innovation assimilation intention.

H4. Perceived organizational justice has a positive effect on individual SSD innovation assimilation intention. 
CMS

12,1

168
H5. Decision-making participation has a positive effect on individual SSD innovation assimilation intention.

Within the TOE framework, the environment dimension belongs to exogenous factors. It has no relation with individual intrinsic motivation. Therefore, we do not include this dimension.

\section{Individual characteristics}

It is difficult for organizational characteristics to exist independently. They are always made up of individual characteristics. The sum of individual characteristics is revealed as organizational characteristics. This means that individual characteristics might be the root cause of individual intrinsic motivation in an innovation environment. Rogers' innovation diffusion theory also emphasizes that individual characteristics are an important factor that affects innovation adoption and assimilation (Rogers, 1995). Therefore, we joined the individual characteristics dimension based on the foregoing discussion and constructed an SSD innovation assimilation "Individual motivation-behavior" research model; this is depicted in Figure 1.

Individual behavior motivation is always determined by a person's needs (Ryan and Deci, 2017). According to the Maslow's theory of needs (Maslow, 1943), individual characteristics include individual needs, interests and feelings. They may involve characteristics such as interest and fun, self-efficacy, attribution needs, autonomy needs, achievement needs and self-actualization needs. Interest and fun are, at first, important. The more interest and fun an individual has, the higher his or her enthusiasm and initiative are reflected in activities, and, accordingly, the stronger his or her motivation is (Utman, 1997). Thus, we propose the following hypothesis:

H6. Interest and fun have a positive effect on individual SSD innovation assimilation intention.

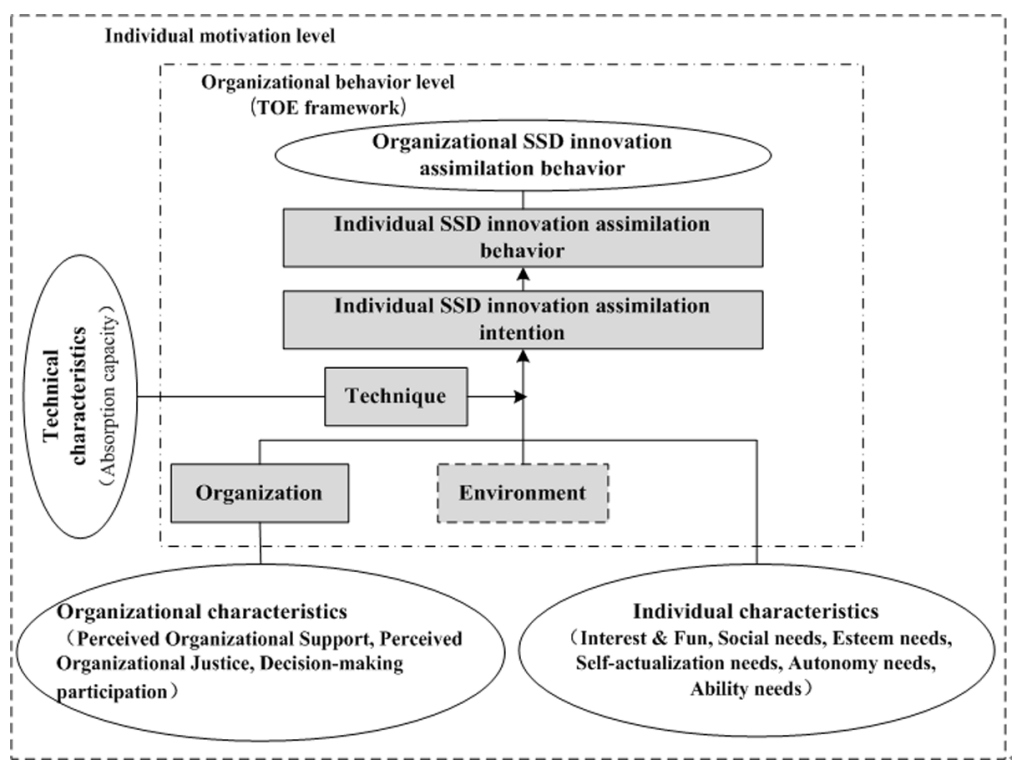

Figure 1.

SSD innovation assimilation "individual motivation-behavior" model 
Maslow stated that human needs are like a ladder; they are hierarchically divided from the lowest to the highest level of needs and into five types: physiological needs, security needs, social needs, respect needs and self-realization needs (Maslow, 1943). Social needs, respect needs and self-actualization needs are the high-level needs. Social needs comprise love, emotion and belonging needs. They refer to the needs of individuals for a sense of safety and belongingness in their interpersonal relationships. Regarding subjective norms of the Theory of Planned Behavior (Deci and Ryan, 1985), which can affect behavioral intention, colleagues are usually important referents for individuals in work-related issues. In social norms of status quo bias theory (Samuelson and Zeckhauser, 1988; Ryan and Deci, 2000), colleague opinion affects behavioral intention. Colleague opinion is also regarded as the salient social characteristic that individuals seek in work environments (Ryan and Deci, 2006). According to the social needs view, colleague relationships reflect social needs, and thus, we propose the following hypothesis:

H7. Social needs have a positive effect on individual SSD innovation assimilation intention.

Esteem needs or respect needs reflect the needs of gaining social acceptance of individual ability and achievement. If respect needs are satisfied and people's self-confidence and enthusiasm for social activities can be engendered, they will regard their lives as valuable. We thus propose $H 8$ :

H8. Esteem needs have a positive effect on individual SSD innovation assimilation intention.

Self-actualization needs refer to needs that can help people achieve personal ideals, develop their personal ability to the greatest degree, achieve self-realization, accept themselves, accept others, enhance problem-solving abilities and complete all tasks that are in line with their own abilities. Human self-actualization experiences include cognitive and emotional aspects (Fishbein and Ajzen, 1975). It reflects strong personality features (Sherrie and Izak, 2006; Guay et al., 2001). Perceived personalization is an emotional factor. It reflects a personal understanding of innovation and represents individual needs. Sherrie stated that perceived personalization will affect personal emotional trust and, subsequently, influence adoption intention. Thus, self-actualization needs with perceived personalization form the fifth group of needs and are also important determinants of SSD innovation assimilation intention:

H9. Self-actualization needs have a positive effect on individual SSD innovation assimilation intention.

Physiological needs and security needs are two basic needs in Maslow's needs theory. Psychological needs include autonomy needs, ability needs and belonging needs according to Deci and Ryan's (1985) self-determination motivation process theory. Events and environment that meet these three needs may promote individual motivation.

Autonomy needs refer to the individual's right to autonomy. When a job is done well, for instance, individuals may get remuneration and feedback, free of degeneration. They will then experience a sense of accomplishment and this will promote individual motivation. Factors such as threats and pressure that are related to security needs will reduce autonomy and, thus, undermine individual motivation (Ryan and Deci, 2000, 2006; Guay et al., 2001). Ability needs refer to personal needs to cultivate ability by means of contact with the environment. While belonging needs are similar to social needs in Maslow's hierarchical 
CMS

12,1

need theory, we do not repeat the corresponding assumption. Rather, we propose the following hypotheses:

H10. Autonomy needs have a positive effect on individual SSD innovation assimilation intention.

H11. Ability needs have a positive effect on individual SSD innovation assimilation intention.

At this stage, we develop the SSD innovation assimilation TOP model based on the level of individual motivation as depicted in Figure 2.

\section{Method}

Research design

We employed empirical research to verify the assumption model presented above. By referring to the items in related literature, we got the initial measurement scales for the investigation. While in light of the characteristics of SSD innovation assimilation, we made some appropriate adjustments and discussed the questionnaire with some domain experts and enterprise managers to ensure the applicability of the questionnaire. The revisions of the measurement scales were reflected in the Appendix Table AI. The questionnaire had a total of 40 items and used a five-point Likert scale to assess the degree of the respondents' agreement with the statements $(1=$ strongly opposed, $5=$ strongly supported $)$.

\section{Procedure}

The survey was divided into three parts. We first conducted semi-structured interviews with some security professionals to consult their advice. The interviewees included some wellknown software engineers, security engineers, security consultants and senior managers in related enterprises. Some experts thought that rather questions in the scales could not describe the current situation of software industry correctly, and some were not specific and difficult to understand. Depending on their advice, we adjusted the scales to make the items

Figure 2.

Proposed model

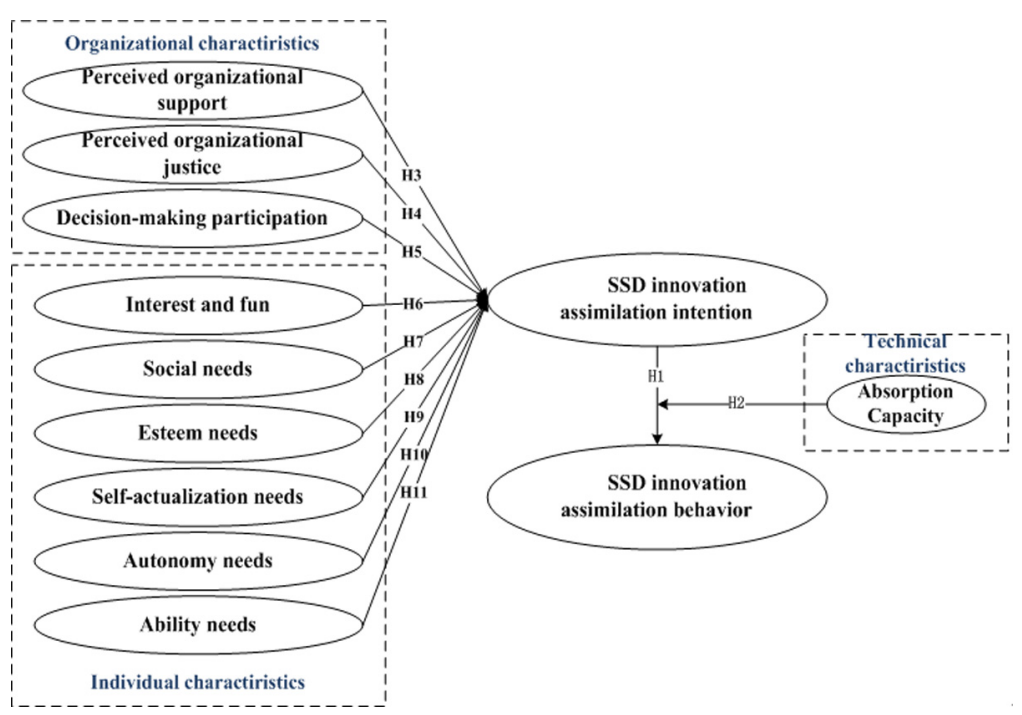


more adaptable to the SSD circumstances, and checked the revisions with the experts again to get their completed questionnaires. Then we circulated the questionnaire among some software development professionals via email so as to get their feedback. In addition, we conducted the survey at a group meeting of the 2015 China Software and Information Service Fair. Of a total of 230 questionnaires collected, a few questionnaires were not effective due to the unreasonable scores, i.e. all questions were marked 1 (strongly opposed) or 5 (strongly supported) by the respondents. So, we marked those responses as invalid and finally got 215 validated questionnaires for further data analysis.

\section{Secure software development}

171

\section{Data analysis}

Regarding related literature and concrete practicability of research objectives, the study used IBM SPSS 19.0 and AMOS 17.0 alternately to analyze data. SPSS AMOS is software that uses structural equations to explore relations between variables. It is easy to do structural equation modeling (SEM), and it quickly creates models to verify the interactions among variables.

First, reliability analysis was used to verify the reliability of the data using SPSS. The results of the data analysis show that the questionnaire scales were reliable; the minimum Cronbach's alpha value was 0.721 , greater than the referenced value 0.7 , which was used to illustrate the trustworthiness of the scale (Ryan and Deci, 2006; Guay et al., 2001).

Thereafter, model fitting was carried out in a structural equation model by AMOS and the results of data validity were obtained. Validity analysis and path analysis were employed to verify the assumption of the model (Eisenberger et al., 2001; Niehoff and Moorman, 1993; Arnold et al., 2000). To gauge the degree of accuracy of measurement of the measuring tool, confirmatory factor analysis was employed. Based on this analysis, the factor loading value of each item was determined, and the values of the average extraction variance (AVE) and composite reliability (CR) were calculated as well. Based on the corrected correlations from the confirmatory factor analysis (CFA) model, the AVE of each of the latent constructs should be higher than the highest squared correlation with any other latent variable. If that is the case, discriminant validity of the construct level is established (Henseler et al., 2014).

All the CR values of the variables were greater than 0.7 and the AVE value was greater than 0.5. The total validity was 0.969 . This is an indication that the model has good convergent validity.

The interaction between the moderator variables and other variables was verified (Ntoumanis and Biddle, 1999; Liu and Sun, 2012; Tomas et al., 2016). Each variable's AVE square root is greater than the correlation index; thus, there is good discriminating validity between the different variables (Figure 3).

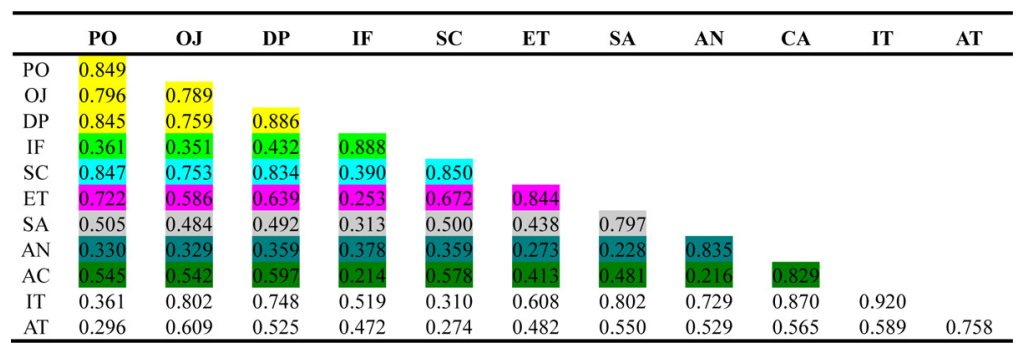

Figure 3. Results of discriminant validity analysis 
CMS

12,1

172

\section{Hypotheses verification}

To explain the relation between the independent and dependent variables, the SEM structural equation model was used to verify and analyze the path of the model. The scale's fit index analysis is shown in Table I, in which the index $\chi^{2} / \mathrm{df}$, RMSEA, GFI, IFI, CFI, PGFI and PCFI all achieved acceptable levels. This means that the model has a good structure overall. The result of the scale's fit index of the proposed model analyzed by AMOS 17.0 is shown in Figure 4.

The relations among the various variables can be estimated by path coefficient and $p$ value. In statistical hypothesis testing, the $p$ value or probability value is the probability for a given statistical model that, when the null hypothesis is true, the statistical summary would be the same as or more extreme than the actual observed results (Ronald and Lazar, 2016). When the value of $p$ is less than 0.05 , it shows that the independent variables have a certain predictive effect on the dependent variables.

According to the results, as depicted in Figure 5, the hypotheses $H 1, H 3, H 4, H 5, H 6, H 7$, $H 8$ and $H 1 O$ are significantly tenable $(p<0.05)$, while the hypotheses $H 9$ and $H 11$ are not

\begin{tabular}{lccccccc}
\hline Fit index & $\chi^{2} / \mathrm{df}$ & RMSEA & GFI & AGFI & CFI & PGFI & PCFI \\
\hline Fit criteria & $<3$ & $<0.1$ & $>0.9$ & $>0.9$ & $>0.9$ & $>0.5$ & $>0.5$ \\
Index of the model & 1.182 & 0.029 & 0.929 & 0.910 & 0.901 & 0.677 & 0.677
\end{tabular}

Table I.

Results of fit index analysis

Notes: $\chi^{2} / \mathrm{df}$ means ratio of chi-square to the degrees of freedom; RMSEA means root mean square error of approximation; GFI means goodness-of-fit index, IFI means incremental fit index and CFI means comparative fit index; PGFI means parsimonious fit index based on GFI and PCFI means parsimonious fit index based on CFI

Figure 4.

AMOS structural model analysis

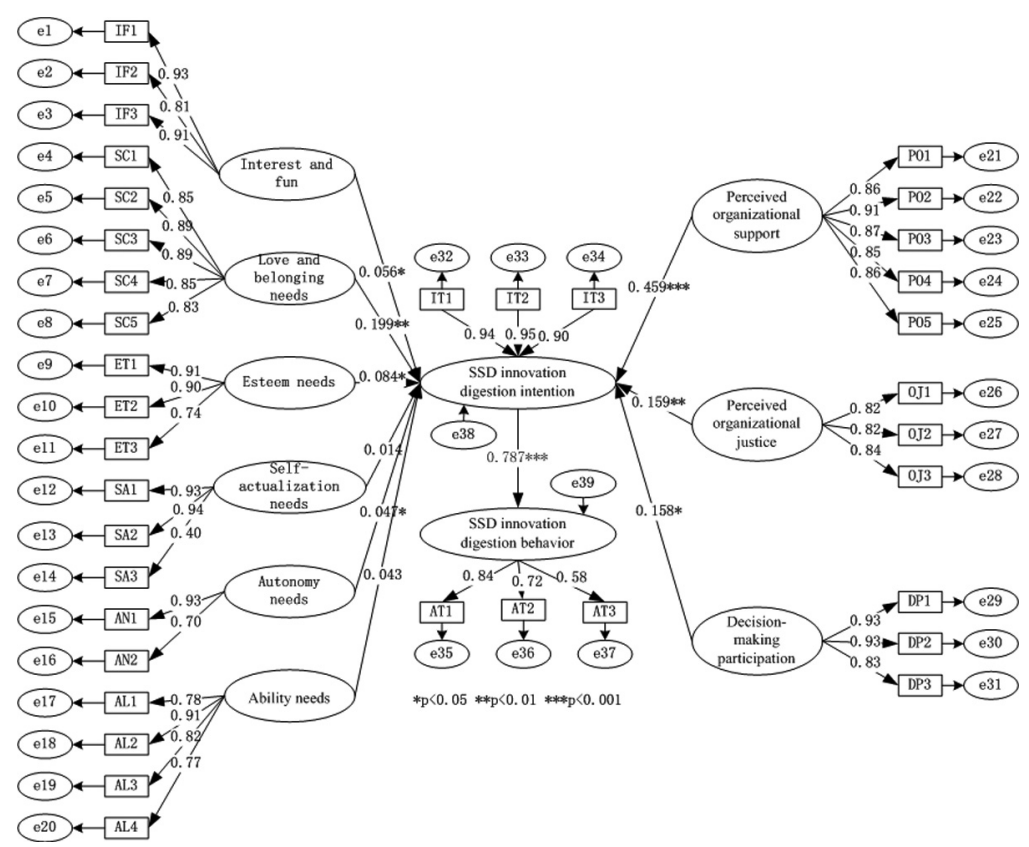


tenable with the $p$ values of 0.689 and 0.132 , respectively $(\phi>0.05)$. This result means that the hypotheses $\mathrm{H1}, \mathrm{H} 3-\mathrm{H} 8$ and $\mathrm{H} 10$ directly describe the relationship of the motivation effect on SSD innovation assimilation intention and behavior. Because the $H 2$ describes the adjustment role of different verification methods, it is discussed in "Regulating effect verification".

By omitting the unsupported hypotheses, $H 9$ and $H 11$, we obtained the overall impact of each variable on SSD innovation assimilation behavior, referred to as the path coefficients analysis among different variables. The results of the effects of the variables on SSD assimilation behavior are shown in Table II. By the parameter estimation value, the variables' direct impacts on the SSD innovation assimilation behavior (AT) arranged from large to small are SSD innovation assimilation intention (IT), perceived organizational support $(\mathrm{PO})$, social needs (SC), perceived organizational justice (OJ), decision-making participation (DP), esteem needs (ET), interest and fun (IF) and autonomy needs (AN).

According to the indirect effect items in Table II, we obtained the overall influence level. In the dimension of organization characteristics, PO was the first important impact factor, followed by OJ, which was slightly more important than DP. The overall effects factors are $0.361,0.125$ and 0.124 , respectively. In the dimension of individual characteristics, the impact factors in the order of importance from high to low were SC, ET, IF and AN. The values of the overall effects are $0.157,0.066,0.044$ and 0.037 , respectively.

\section{Regulating effect verification}

A verification of $H 2$, the regulating effect of absorption ability on SSD innovation assimilation intention and SSD innovation assimilation behavior follows.

\begin{tabular}{ccccccc}
\hline $\begin{array}{c}\text { Relationship } \\
\text { among variables }\end{array}$ & $\begin{array}{c}\text { Parameter } \\
\text { estimation value }\end{array}$ & S.E. & C.R. & P & Conclusion & $\begin{array}{c}\text { Relationship } \\
\text { among variables }\end{array}$ \\
\hline PO $\rightarrow$ IT & 0.459 & 0.098 & 4.706 & $* * *$ & H3 & support \\
SJ $\rightarrow$ IT & 0.159 & 0.065 & 2.696 & 0.007 & H4 & support \\
support
\end{tabular}

Figure 5.

Conclusion of hypothesis test

\begin{tabular}{|c|c|c|c|c|c|}
\hline Impact factors & Variables & Direct effect & Indirect effect & Overall effect & \\
\hline \multirow[t]{3}{*}{ Organizational characteristics } & $\mathrm{PO}$ & 0.459 & $0.459 \times 0.787$ & 0.361 & \\
\hline & OJ & 0.159 & $0.159 \times 0.787$ & 0.125 & \\
\hline & $\mathrm{DP}$ & 0.158 & $0.158 \times 0.787$ & 0.124 & \\
\hline \multirow[t]{4}{*}{ Individual characteristics } & IF & 0.056 & $0.056 \times 0.787$ & 0.044 & \\
\hline & $\mathrm{SC}$ & 0.199 & $0.199 \times 0.787$ & 0.157 & Table II. \\
\hline & ET & 0.084 & $0.084 \times 0.787$ & 0.066 & Variables' effects on \\
\hline & $\mathrm{AN}$ & 0.047 & $0.047 \times 0.787$ & 0.037 & $\begin{array}{l}\text { variables eIrects on } \\
\text { SSD innovation }\end{array}$ \\
\hline Assimilation intention & IT & 0.787 & 0.787 & 0.787 & assimilation behavior \\
\hline
\end{tabular}


CMS

12,1

174

In statistics and regression analysis, moderation occurs when the relation between two variables depends on a third variable. The third variable is referred to as the moderator variable or simply the moderator, and the effect of a moderating variable is characterized statistically as an interaction (Cohen and Levinthal, 1990). Regulated variables in a structural equation model describe a moderating role in a relation. If the relation between the two variables (such as the relation between $\mathrm{Y}$ and $\mathrm{X}$ ) is a function of the variable $\mathrm{M}$, we called M regulated variable (Ryan and Deci, 2006).

In this study, variables involved in the right half of the model are absorption capacity (AC), SSD innovation assimilation intention (IT) and SSD innovation assimilation behavior (AT). We constructed the model with IT, AC and AT as M1, and the model with the additional variable IT $\times \mathrm{AC}$ as M2. That means M2 can be obtained by the regression of M1. First, we averaged the items of the three latent variables and generated a new value. We then carried out centralized processing. Finally, we conducted regression analysis and calculated the interaction item "IT $\times$ AC", observing whether the regression coefficient was significant. The regulation results of the AC of the interaction between SSD IT and AT by regression analysis are shown in Table III.

An examination of Table III reveals that the significance value F of M1 is 69.534, which shows that the regression effect is remarkable. The value of $R^{2}$ is 0.396 . It means the proportion of the two independent variables' joint explanation of the dependent variables is 39.6 per cent. The value of $\mathrm{F}$ in M2 is 53.336 and the regression effect is also significant. The interaction item $(\mathrm{IT} \times \mathrm{AC}$ ) reached a significant level $(\mathrm{Sig}<0.01)$, indicating that absorption capacity plays a regulated role in the relationship between SSD IT and SSD AT. Besides, the values of $R^{2}$ in $\mathrm{M} 2$ is 0.431 , an increase of 3.5 per cent compared to M1, which means that after joining the regulated variable, M2 is more optimized than M1. As the regression coefficient of the interaction item "IT $\times \mathrm{AC}$ " is positive, absorption capacity has a positive regulated effect on SSD innovation assimilation intention to behavior. Therefore, H2 is supported.

From the above analysis, the verification conclusion of the hypothesis test is shown in Figure 5. The hypotheses $H 1, H 3, H 4, H 5, H 6, H 7, H 8$ and $H 1 O$ are supported. With reference to $H 1$, it means that SSD IT has a positive influence on SSD AT. With reference to the support of $H 3, H 4$ and $H 5$, it means that PO, OJ and DP of organizational characteristics all have an effect on SSD IT, and their influence level is slightly less according to Table II. With reference to the support of H6, H7, H8 and $H 10$, it means that for individual characteristics, IF, SC, ET and AN all have a positive influence on SSD IT, and impact factors in the order of importance from high to low are

Table III.

Regulation results of absorption capacity by regression analysis

\begin{tabular}{|c|c|c|c|c|c|c|c|c|}
\hline \multirow[b]{3}{*}{$\begin{array}{l}\text { Independent } \\
\text { variables }\end{array}$} & \multicolumn{8}{|c|}{ Dependent variables: SSD innovation AT } \\
\hline & \multicolumn{4}{|c|}{ Model 1} & \multicolumn{4}{|c|}{ Model 2} \\
\hline & $\begin{array}{l}\text { Regression } \\
\text { coefficient }\end{array}$ & Sig. & Tolerance & VIF & $\begin{array}{c}\text { Regression } \\
\text { coefficient }\end{array}$ & Sig. & Tolerance & VIF \\
\hline IT & 0.421 & $0.000 * *$ & 0.638 & 1.566 & 0.464 & $0.000 * *$ & 0.617 & 1.619 \\
\hline $\mathrm{AC}$ & 0.279 & $0.000 * *$ & 0.638 & 1.566 & 0.238 & $0.000 * *$ & 0.620 & 1.612 \\
\hline $\mathrm{IT} \times \mathrm{AC}$ & & & & & 0.191 & $0.000 * *$ & 0.962 & 1.039 \\
\hline$R^{2}$ & 0.396 & & & & 0.431 & & & \\
\hline$F$ & 69.534 & & & & 53.336 & & & \\
\hline Sig. & 0.000 & & & & 0.000 & & & \\
\hline
\end{tabular}


SC, ET, IF and AN. H9 and H11 are not supported; this means that self-actualization needs and ability needs do not influence SSD innovation assimilation intention. In addition, $H 2$ is supported; this means absorption ability (AC) plays a regulated role from SSD IT to AT.

\section{Results}

In an effort to analyze the above structural function, post-analysis was conducted on this study's survey. Figure 6 was then created, which adapted Figure 2 in light of the survey data analysis. Figure 6 addresses SSD innovation assimilation based on the level of individual motivation from various perspectives, and the seven factors that were found in this study are likely to be potential determinants.

From the perspective of organizational characteristics, perceived organizational support, perceived organizational justice and decision-making participation will influence individual SSD IT, and their degree of influence is diminishing. From the perspective of individual characteristics, interest and fun, social needs, esteem needs and autonomy needs all have a positive significant influence on individual SSD assimilation innovation intention; furthermore, social needs is the most important factor followed by esteem needs. These are followed by interest and fun and autonomy needs.

The right side of Figure 6 addresses the relationship between individual SSD AI and AT. Individual SSD AI has a significant positive effect on SSD AT. While user interview indicates that even though a user perceives his AI, he or she might not show AT. Absorption capacity plays an important positive regulated role in this process. If a user has poor absorption ability, he would be unable to apply the SSD method in his or her software development because of its complexity.

\section{Discussion}

This study considers the individual intention and behavior of SSD innovation assimilation in the complete framework of an organization and explores the underlying psychological motivation to discover how to stimulate individuals to achieve the overall objectives of an organization for the assimilation of SSD innovation. Based on our TOP model and research findings, the discussion is divided into the following three dimensions: organizational, individual and technical.

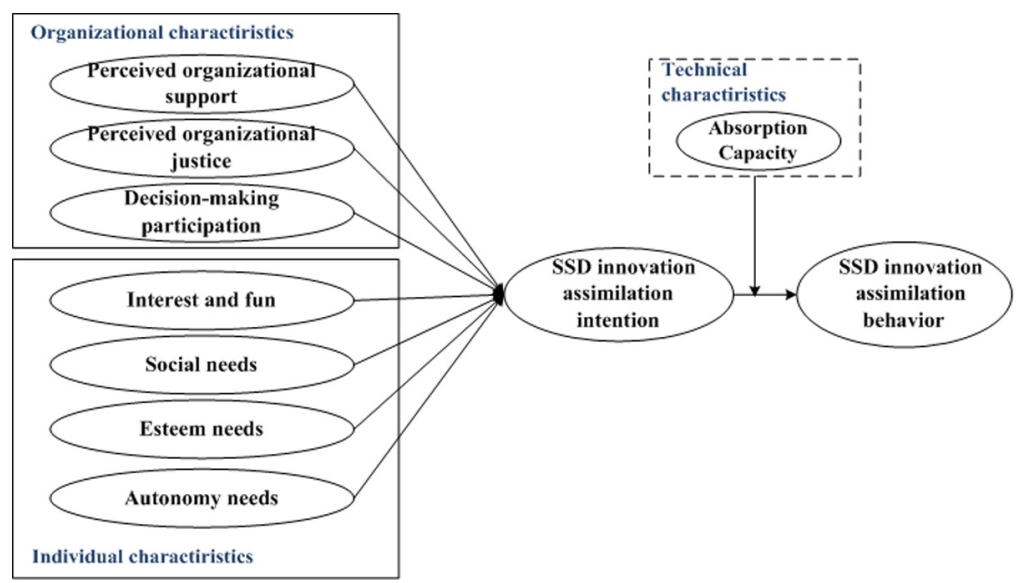

Figure 6.

SSD innovation assimilation model on individual motivation level - verified model 
CMS

12,1

\section{Organizational dimension}

Organizational factors play a significant role in employees' job performance; it makes them feel that the organization is fair and supportive. According to the results of the analysis, perceived organizational support, perceived organizational justice and decision-making participation are important determining factors. The level of their effect diminishes gradually.

Perceived organizational support means employees believe that their organization values their contributions, cares about their well-being and fulfills their socio-emotional needs. In an organization, an employee's contribution relates to his individual's life, remuneration and benefits, as well as the realization of individual goals and value. Thus, their perceived organizational support will first be enhanced.

Perceived organizational justice is the second important factor among the organizational elements. It is about an individual's perceptions of these decisions and can influence the individual's subsequent attitudes and behaviors. Justice in organizations can include issues related to perceptions of fair pay, equal opportunities for promotion and personnel selection procedures. Managers should take these factors into account to promote fairness in their daily work. There are internal relations between the two factors as they eventually result in the employees' assimilation behavior. If employees experience organizational support from their enterprises, they will enhance their perceived organizational justice by matching work responsibility and return in SSD practice.

Decision-making participation is also an important influencing factor. If individuals can perceive the sense of justice first, then they will put in more effort to participate in decisionmaking. To achieve these goals, managers should appropriately allow employees to experience decentralization and authorization, to provide them the opportunity to take part in decision-making. In addition, individuals should be encouraged to present their opinions in decision-making, and any needs and suggestions should be considered fully. However, in most cases, this is difficult to achieve and negotiations may be needed.

\section{Individual dimension}

According to our findings, some individual factors are the key determinants that influence SSD innovation assimilation. To be specific, the effects of SC and ET on innovation assimilation process are the most important, followed by IF and AN.

$\mathrm{SC}$ is the most important factor in our study. In the process of the SSD innovation assimilation, individual love and belongingness emotions should be paid attention first. The satisfaction of individual self-respect, self-confidence and achievement are important needs. To achieve these goals, individuals should communicate with software security experts and peers in the implementation of the new method and solve problems of challenging work. They should try their best to develop an individual social network, master more means of communication and enhance an individual bonding effect with colleagues and the team. Through with social recognition in the organization, individuals can realize their own values and then apply their enthusiasm in SSD.

ET presents the typical human desire to be accepted and valued by others; through social recognition, individual esteem needs can be met. They will feel confident and responsible, and be encouraged to complete seemingly impossible task.

IF can motivate people to keep on engaging in certain activities; if employees have a strong interest in software development and can derive a great deal of fun from it, this will allow them to remain positive and optimistic in the process of innovation assimilation, which will be helpful to improve the efficiency of assimilation. Although individual interest and fun are not the most important factor to what we expected according our results, we 
should still pay attention to its cultivation in SSD assimilation process, otherwise we may encounter strong resistance from employees.

AN refers to the individual's right to autonomy. People with high autonomy needs are willing to take the initiative of learning new things, and they want to make decisions by themselves rather than relying on others. High autonomy will promote the notion of people learning and mastering new skills that are included in SSD method autonomously. Managers should be conscious of providing employees with independence of choice and create an autonomous working environment for them. When people come across highly complex goals, they need to be provided sufficient time to work toward the goal, improve performance, practice and learn what is necessary for success (Su and Su, 2017).

In practices, if SC and ET can be met effectively during the process of solving problems and learning new skills, people will be inspired to address challenging issue. While IF and $\mathrm{AN}$ are often placed in a secondary position, this will result in them getting the job done even if they are not interested in the job or irrespective of whether they want it or not. This result is in accordance with the goal-setting theory.

\section{Technical dimension}

According to the technical dimension, AC plays a positive moderating role in the process of individual SSD AI to AT. AC represents an employee's technical level during the process of $\mathrm{SSD}$ assimilation. To improve individual $\mathrm{AC}$ at the transformation stage, relevant education and training of SSD, self-study and courses from local experts and other peers should be encouraged. By improving the AC and SSD AI, SSD AT could be promoted.

Overall, in the process of SSD innovation assimilation, the organizational factors should be considered significantly and attention should also be given to underlying psychological characteristics based on the level of individual motivation. To promote the conversion rate of AI to AT, AC should be focused on individuals as well as organizations by constructing a learning organization. Through the continuous improvement of the whole team's absorption capacity, the SSD innovation deployment will become more feasible.

\section{Conclusion}

In this study, we developed a TOP model to understand how to promote SSD innovation assimilation from the perspective of individual motivation. Key findings revealed that two types of individual motivation can influence SSD innovation assimilation, namely, potential organization support and individual needs. On organizational dimension, perceived organizational support, perceived organizational justice and decision-making participation are important determining factors. The level of their effect diminishes gradually. On individual dimension, the effects of social needs and esteem needs on innovation assimilation intention are the most important, followed by individual interest and fun and autonomy needs. Furthermore, absorption capability was found to play a regulated function in the transition of SSD assimilation intention to behavior.

The findings fill the gap of the research on organizational assimilation behavior and individual motivation in the context of SSD complex innovation, and provide management of software development organization with empirically based conceptualization to guide their personnel incentive policymaking.

\section{Research limitations and future work}

Although some demonstrable key findings have been achieved in this study, there are still some research limitations. On the one hand, due to the limit of the survey scale and time, the collection of data was restricted in that further analysis was not possible. In particular, H9 
CMS

12,1

and $H 11$ could not be verified. Thus, self-actualization needs and ability needs have no positive predictive role in SSD innovation assimilation. The reason may lie in the limitation of our respondents' choices. Further studies should enlarge the scope of the respondents, to make the sample distribution more homogeneous to guarantee the research is more representative and accurate. On the other hand, the relation among dependent and independent variables was not be analyzed in this paper, and a lack of a comprehensive study of SSD innovation assimilation with a combination of external factors and internal factors. Future research will be conducted in conjunction with current work and will address these issues.

\section{References}

Ajzen, I. (2002), "Perceived behavioral control, self-efficacy, locus of control and the theory of planned behavior", Journal of Applied Social Psychology, Vol. 32 No. 4, pp. 665-683.

Amabile, T.M. (1985), "Motivation and creativity: effects of motivational orientation on creative writers", Journal of Personality \& Social Psychology, Vol. 48 No. 2, pp. 393-399.

Anthony, M.G. (2012), "An integrated model of goal-focused coaching: An evidence-based framework for teaching and practice”, International Coaching Psychology Review, Vol. 7 No. 2, pp. 146-165.

Arnold, J.A., Arad, S. and Rhoades, J.A. (2000), "The empowering leadership questionnaire: the construction and validation of a new scale for measuring leader behaviors", Journal of Organizational Behavior, Vol. 21 No. 3, pp. 249-269.

Bandura, A. (1995), Self-Efficacy in Changing Societies, Cambridge University Press, Cambridge.

Bosua, R., Gloet, M., Kurnia, S., et al. (2013), "Telework, productivity and wellbeing: an Australian perspective", Telecommunications Journal of Australia, Vol. 63 No.1, available at: https://doi.org/ 10.7790/tja.v63i1.390

Cohen, W.M. and Levinthal, D.A. (1990), "Absorptive capacity: a new perspective on learning and innovation”, Administrative Science Quarterly, Vol. 35 No. 1, pp. 128-152.

Davis, F.D. (1989), "Perceived usefulness, perceived ease of use, and user acceptance of information technology", MIS Quarterly, Vol. 13 No. 3, pp. 319-340.

Davis, F.D., Bagozzi, R.P. and Warshaw, P.R. (2006), "Extrinsic and intrinsic motivation to use computers in the workplace", Journal of Applied Social Psychology, Vol. 22 No. 14, pp. 1111-1132.

Deci, E.L. and Ryan, R.M. (1985), Intrinsic Motivation and Self-determination in Human Behavior, Plenum Press, New York, NY.

Deci, E.L., Nezlek, J. and Sheinman, L. (1980), "Characteristics of the rewarder and intrinsic motivation of the rewardee", Journal of Personality \& Social Psychology, Vol. 40 No. 1, pp. 1-10.

Duan, M.S., Zhang, X.L. and Gu, S.H. (2001), "Innovation diffusion model based on the theory of the micro decision-making", System Engineering Theory and Practice, Vol. 21 No. 6, pp. 46-51.

DuBrin, A.J. (2012), Essentials of Management, Cengage South-Western, Mason, OH.

Eby, L.T., Freeman, D.M., Rush, M.C. and Lance, C.E. (1999), "Motivational bases of affective organizational commitment: a partial test of an integrative theoretical model", Journal of Occupational and Organizational Psychology, Vol. 72 No. 4, pp. 463-483.

Eisenberger, R., Armeli, S., Rexwinkel, B., Lynch, P.D. and Rhoades, L. (2001), "Reciprocation of perceived organizational support", Journal of Applied Psychology, Vol. 86 No. 1, pp. $42-51$.

Fichman, R.G. and Carroll, W.E. (1999), The Diffusion and Assimilation of Information Technology Innovations, Pinnaflex Educational Resources, Cincinnati, $\mathrm{OH}$.

Fichman, R.G. and Kemerer, C. (1999), "The illusory diffusion of innovation: an examination of assimilation gaps", Information System Research, Vol. 10 No. 3, pp. 255-275.

Fishbein, M. and Ajzen, I. (1975), Belief, Attitude, Intention and Behavior: An Introduction to Theory and Research, Addison-Wesley, Reading, MA. 
Gagnon, Y.C. and Dragon, J. (2002), "The impact of technology on organizational performance", available at: www.optimumonline.ca/pdf/28-1/technology.pdf (accessed 14 December 2015).

GalUvan, J.M. (2001), "Organizational adoption and assimilation of complex technological innovations: development and application of a new framework", ACM SIGMIS Database, Vol. 32 No. 3, pp. 51-85.

Guay, F., Boggiano, A.K. and Vallerand, R.J. (2001), "Autonomy support, intrinsic motivation and perceived competence: conceptual and empirical linkages", Personality and Social Psychology Bulletin, Vol. 27 No. 6, pp. 643-650.

Henseler, J., Ringle, C.M. and Sarstedt, M. (2014), “A new criterion for assessing discriminant validity in variance-based structural equation modeling", Journal of the Academy of Marketing Science, Vol. 43 No. 1, pp. 115-135.

Hsieh, P.A.J.J. and Wang, W. (2007), "Explaining employees' extended use of complex information systems", European Journal of Information Systems, Vol. 16 No. 3, pp. 216-227.

Ives, B. and Jarvenpaa, S.L. (1991), "Applications of global information technology: key issues for management”, Management Information Systems Quarterly, Vol. 15 No. 1, pp. 33-49.

Karl, E.W. (1979), The Social Psychology of Organizing, 2nd ed., Random House, New York, NY.

Ke, W. and Wei, K.K. (2015), "Exploratory usage of enterprise systems: the joint effects of intrinsic motivation and psychological empowerment", Proceedings of Pacific Asia Conference on Information Systems (PACIS), AIS Electronic Library, paper 32.

Lapointe, L. and Rivard, S. (2007), "A triple take on information system implementation”, Organization Science, Vol. 18 No. 1, pp. 89-107.

Li, X., Hsieh, P.A. and Rai, A. (2013), "Motivational differences across post-acceptance information system usage behaviors: an investigation in the business intelligence systems context", Information Systems Research, Vol. 24 No. 3, pp. 659-682.

Lin, Z. (2002), "The dynamics of inter-organizational ties during crises: empirical evidence and computational analysis", Simulation Modelling Practice and Theory, Vol. 10 No. 5, pp. 387-415.

Liu, L.C. and Sun, K. (2012), "Empirical research on user satisfaction and continued use of SaaS outsourcing service", Journal of Information Resources Management, Vol. 2 No. 1, pp. 26-32.

Liu, L., Feng, Y.Q., Hu, Q. and Huang, X.J. (2011), "From transactional user to VIP: how organizational and cognitive factors affect ERP assimilation at individual level", European Journal of Information Systems, Vol. 20 No. 2, pp. 186-200.

Locke, E.A. and Latham, G.P. (2002), "Building a practically useful theory of goal setting and task motivation", American Psychologist, Vol. 57 No. 9, pp. 705-717.

Maruping, L.M. and Magni, M. (2015), "Motivating employees to explore collaboration technology in team contexts”, MIS Quarterly, Vol. 39 No. 1, pp. 1-16.

Maslow, A.H. (1943), "A theory of human motivation”, Psychological Review, Vol. 50 No. 4, pp. 370-396.

Meyer, D.A. and Goes, B.J. (1988), "Organizational assimilation of innovations: a multi-level contextual analysis", Academy of Management Journal, Vol. 31 No. 1, pp. 897-923.

Mishra, K., Boynton, L. and Mishra, A. (2014), "Driving employee engagement: the expanded role of internal communications", International Journal of Business Communication, Vol. 51 No. 2, p. 183.

Niehoff, B.P. and Moorman, R.M. (1993), "Justice as a mediator of the relationship between methods of monitoring and organizational citizenship behavior", Academy of Management Journal, Vol. 36 No. 3, pp. 327-336.

Ntoumanis, N. and Biddle, S.J. (1999), "A review of motivational climate in physical activity”, Journal of Sports Sciences, Vol. 17 No. 8, pp. 643-665.

Rhoades, L. and Eisenberger, R. (2002), "Perceived organizational support: a review of the literature", Journal of Applied Psychology, Vol. 87 No. 4, pp. 698-714.

Ricahrd, M. and Ryan, E.L. (2000), "Intrinsic and extrinsic motivations: classic definitions and new directions", Contemporary Educational Psychology, Vol. 25 No. 1, pp. 54-67. 
CMS

12,1

Rogers, E.M. (1995), Diffusion of Innovations, The Free Press, New York, NY.

Ronald, L.W. and Lazar, N.A. (2016), "The ASA's statement on p-values: context, process and purpose", The American Statistician, Vol. 70 No. 2, pp. 129-133.

Ryan, R. and Deci, E. (2000), "Self-determination theory and the facilitation of intrinsic motivation, social development and well-being", American Psychologist, Vol. 55 No. 1, pp. 68-78.

Ryan, R. and Deci, E. (2006), "Self-regulation and the problem of human autonomy: does psychology need choice, self-determination and will", Journal of Personality, Vol. 74 No. 6, pp. 1557-1585.

Ryan, R.M. and Deci, E.L. (2017), Self-determination Theory: Basic Psychological Needs in Motivation, Development and Wellness, Guilford Publications, New York, NY.

Samuelson, W. and Zeckhauser, R. (1988), "Status quo bias in decision making”, Journal of Risk and Uncertainty, Vol. 1 No. 1, pp. 7-59.

Scott, T.R. (2005), "Effects of achievement motivation on behavior", available at: www. personalityresearch.org/papers/rabideau.html (accessed 15 December 2016).

Sherrie, Y.X.K. and Izak, B. (2006), "The effects of personalization and familiarity on trust and adoption of recommendation agents”, MIS Quarterly, Vol. 30 No. 4, pp. 941-960.

Song, M.Q., Chen, D.H. and Mkoba, E.S. (2014), "Secure software development assimilation: effects of external pressures and roles of internal factors", International Journal of Secure Software Engineering, Vol. 5 No. 4, pp. 32-55.

Su, Y.Y. and Su, T.Y. (2017), "Performance aspiration, industrial search and R\&D investment among chinese firms: dstinguishing isomorphism and differentiation rationales", Chinese Management Studies, Vol. 11 No. 2, pp. 270-283, available at: https://doi.org/10.1108/CMS02-2017-0032

Tomas, G.T., Dan, S.C., Ning, L. and Dave, T.W. (2016), "Joint effects of creative self-efficacy, positive and negative affect on creative performance", Chinese Management Studies, Vol. 10 No. 4, pp. 726-745, available at: https://doi.org/10.1108/CMS-06-2016-0126

Tornatzky, L.G., Fleischer, M. and Chakrabarti, A.K. (1990), The Processes of Technological Innovation, Lexington Books, Lexington.

Utman, C.H. (1997), "Performance effects of motivational state: a meta-analysis", Personality and Social Psychology Review, Vol. 1 No. 2, pp. 170-182.

Wallace, J.C., Butts, M.M., Johnson, P.D., Stevens, F.G. and Smith, M.B. (2016), “A multi-level model of employee innovation", Journal of Management, Vol. 42 No. 4, pp. 982-1004.

Wesley, M.C. and Levinthal, D. (1990), "Absorptive capacity: a new perspective on learning and innovation”, Administrative Science Quarterly, Vol. 35 No. 1, pp. 128-152.

Zhang, H.X. and Xie, Y. (2008), "Model of motivation process influence on teenager network game behavior", Journal of Psychology, Vol. 40 No. 12, pp. 1275-1286.

Zhang, W.Q., Jex, S., Peng, Y.S. and Wang, D.D. (2017), "Exploring the effects of job autonomy on engagement and creativity: the moderating role of performance pressure and learning goal orientation”, Journal of Business and Psychology, Vol. 32 No. 3, pp. 235-251.

\section{Further reading}

Amabile, T.M. (1996), Creativity in Context: Update to the Social Psychology of Creativity, Westview Press, Boulder, CO, pp. 100-101.

Do, B.R., Yeh, P.W. and Madsen, J. (2016), "Exploring the relationship among human resource flexibility, organizational innovation and adaptability culture", Chinese Management Studies, Vol. 10 No. 4, pp. 657-674, available at: https://doi.org/10.1108/CMS-01-2016-0022

Grant, M.A. (2012), “An integrative goal-focused approach to executive coaching”, International Coaching, Psychology Review, Vol. 7 No. 2, pp. 145-165. 
Hou, J.T., Wen, Z.L. and Cheng, Z.J. (2004), Structural Equation Model and Its Application, Education Science Press, Beijing.

Irene, M.Y. and Kankanhalli, A.W. (2007), "Investigation of IS professionals' intention to practice secure development of applications", International Journal of Human-Computer Studies, Vol. 65 No. 1, pp. 29-41.

Jacob, C., Patricia, C., Stephen, G.W. and Aiken, L.S. (2003), Applied Multiple Regression/Correlation Analysis for the Behavioral Sciences, Erlbaum, Mahwah, NJ, pp. 302-353.

Liang, C.Y. and Chang, C.C. (2013), "Intrinsic motivation as a mediator on imaginative capability development", Thinking Skills and Creativity, Vol. 8 No. 4, pp. 109-119.

Lipner, S. (2004), "The trustworthy computing security development lifecycle", Computer Security Applications Conference, pp. 2-13.

Ma, X.Y., Lou, Z.S. and Liu, C.Y. (2011), "Path analysis of the pilot adaptation and anxiety personality's influence on mental health", Journal of Rehabilitation Medicine in China, Vol. 20 No. 4, pp. 332-334.

Mathienson, K. (1991), "Predicting user intention: comparing the technology acceptance model with the theory of planned behavior", Information Systems Research, Vol. 2 No. 3, pp. 173-191.

Paramitha, A. and Indarti, N. (2014), "Impact of the environment support on creativity: assessing the mediating role of intrinsic motivation", Procedia - Social and Behavioral Sciences, Vol. 115 No. 21, pp. 102-114.

Rachelle, B., Nina, E. and Janet, S. (2103), "Social networks, social media and absorptive capacity in regional small and medium enterprises (SMES) in Australia", Australian and International Journal of Rural Education, Vol. 23 No. 1, p. 117.

Said, S.A. (2014), "Empirical investigation of e-learning acceptance and assimilation: a structural equation model", Applied Computing and Informatics, Vol. 12 No. 1, pp. 27-50, doi: 10.1016/j. aci.2014.09.001.

Schneider, L.M. and Bethany, M.K. (2013), "Psychological need satisfaction, intrinsic motivation and affective response to exercise in adolescents", Psychology of Sport and Exercise, Vol. 14 No. 5, pp. 776-785.

Taylor, S. and Todd, P. (1995), "Understanding information technology usage: a test of competing models", Information Systems Research, Vol. 6 No. 2, pp. 144-176. 


\begin{tabular}{lll}
\hline Component & Measurement items & Reference \\
\hline $\begin{array}{l}\text { Perceived } \\
\text { organizational }\end{array}$ & $\begin{array}{l}\text { PO1: Organization accepts individual contribution to the } \\
\text { organization in secure system development }\end{array}$ & $\begin{array}{l}\text { Eisenberger } \text { et al } . \\
(2001)\end{array}$ \\
support (PO) & $\begin{array}{l}\text { PO2: Organization concerns individual life, remuneration } \\
\text { and benefits }\end{array}$ & \\
& PO3: Contributions are in conformity with compensation & \\
& $\begin{array}{l}\text { PO4: Organization gives full consideration to the } \\
\text { realization of individual goals and value } \\
\end{array}$ & \\
& PO5: Organization supports the development of personal \\
& interests related to secure software development &
\end{tabular}

Perceived organizational justice (OJ)

Decision-making participation (DP)

Interest and Fun (IF)

Social needs(SC)

Esteem needs (ET)

\section{Table AI.}

The measurements of survey component and resource
OJ1: Considering the responsibilities of the individual, organization's reward is fair

OJ2: Organization gives full consideration of needs and suggestions of all types of person

OJ3: Organization can consider the actual situation of individuals when makes decisions related to work

DP1: Leaders gives everyone opportunity to present their opinions

DP2: Leaders adopt our suggestions when they make a decision which will impact us

DP3: Leaders consider our advice when the idea is not in accord with us

IF1: Preference degree for software vulnerabilities, risk analysis, security coding and such issues

IF2: Preference degree to practice new security coding method

IF3: Emotion influence degree by the good or bad results of the secure software development testing

$\mathrm{SC1}$ : Learn a lot of communication means in the process of contacting with secure software experts and peers SC2: Learn better to get along with people through new development methods practice

SC3: Develop interpersonal relationship through solving problems in new task

SC4: Make a close relationship with colleagues in secure system development practice

SC5: Generate stronger dependence on the team

ET1: Ability and achievements are recognized through the secure system development practice

ET2: Organizational and social recognition makes people full of confidence and enthusiasm for work

ET3: The practice of secure system development method makes people realize their own value
Niehoff and Moorman (1993)

Arnold et al. (2000)

Maslow (1943) and Lin (2002)

Lin (2002) and Zhang and Xie (2008)

Maslow (1943)

(continued) 


\begin{tabular}{|c|c|}
\hline Component & Measurement items \\
\hline $\begin{array}{l}\text { Self-actualization } \\
\text { needs (SA) }\end{array}$ & $\begin{array}{l}\text { SA1: Easier to achieve their ideal and display the ability } \\
\text { to the maximum } \\
\text { SA2: Improve the ability to solve problems and enhance } \\
\text { initiative to work } \\
\text { SA3: Strengthen the independent ability to deal with } \\
\text { problems and complete task match with their ability }\end{array}$ \\
\hline $\begin{array}{l}\text { Autonomy needs } \\
\text { (AN) } \\
\text { Ability needs (AL) }\end{array}$ & $\begin{array}{l}\text { AN1: Learn skills your own like } \\
\text { AN2: Choose methods to complete the work by yourself } \\
\text { AL1: Personal performance is good in secure system } \\
\text { development practice } \\
\text { AL2: Satisfaction degree of your own performance in } \\
\text { secure system development activities } \\
\text { AL3: Perceived personal development skill enhanced } \\
\text { degree } \\
\text { AL4: Support secure system development practice since } \\
\text { you are very good at it }\end{array}$ \\
\hline $\begin{array}{l}\text { Absorption capacity } \\
\text { (AC) }\end{array}$ & $\begin{array}{l}\text { AC1: Have a certain practical experience, background } \\
\text { and information processing ability } \\
\text { AC2: Participate in secure system development related } \\
\text { training } \\
\text { AC3: Have strong personal adapt ability }\end{array}$ \\
\hline Intention (IT) & $\begin{array}{l}\text { IT1: Support organization to adopt secure system } \\
\text { development method } \\
\text { IT2: Plan to use secure system in work } \\
\text { IT3: Plan to use secure system methods again }\end{array}$ \\
\hline Behavior (AT) & $\begin{array}{l}\text { AT1: Products have a better safety performance than } \\
\text { expected after introducing secure system development } \\
\text { methods } \\
\text { AT2: Often use secure system development methods to } \\
\text { finish work better } \\
\text { AT3: Recommend secure system development methods } \\
\text { to others }\end{array}$ \\
\hline
\end{tabular}

Reference

Maslow (1943), Lin

(2002)

Secure

software

development

183

Zhang and Xie (2008)

Zhang and Xie (2008)

Liu et al. (2011)

Liu et al. (2011)

Liu et al. (2011)

Table AI.

For instructions on how to order reprints of this article, please visit our website:

www.emeraldgrouppublishing.com/licensing/reprints.htm

Or contact us for further details: permissions@emeraldinsight.com 